\title{
Could pollution levels, characteristics, sources of PAHs in atmospheric particulate matter break the Hu line?
}

\section{Yan Shi \\ Longdong University \\ Ning Zhang \\ Longdong University \\ Yingqiang Wang \\ Longdong University \\ Yibin Ren \\ Longdong University}

Yongfu Wu ( $\square$ yongfu2006@126.com )

Longdong University https://orcid.org/0000-0002-2031-394X

\section{Research Article}

Keywords: Hu line, Polycyclic aromatic hydrocarbons, Pollution, Atmospheric particulate matter, China

Posted Date: March 2nd, 2021

DOl: https://doi.org/10.21203/rs.3.rs-164512/v1

License: (c) (i) This work is licensed under a Creative Commons Attribution 4.0 International License. Read Full License 


\section{Could pollution levels, characteristics, sources of PAHs in}

\section{2 atmospheric particulate matter break the $\mathrm{Hu}$ line?}

3

4 Yongfu Wu*, Yan Shi, Ning Zhang, Yingqiang Wang, Yibin Ren

5 College of Agriculture and Forestry Science and Technology, Longdong University,

6 China

\section{Abstract}

Were the pollution levels, characteristics and sources of PAHs related to the population and GDP on both sides of the Hu line? What was the relationship between them? The study summarizes and discusses available data for PAHs in atmospheric particulate matter (PM) from 93 above prefecture-level cities in China in 2000-2019. The results suggested that the concentration of PAHs in PM varied with 7 regions of China in descending order: Northeast $(\mathrm{NE})>$ North China $(\mathrm{NC})>$ Northwest $(\mathrm{NW})>$ South China $(\mathrm{SC})>$ Southwest $(\mathrm{SE})>$ Central China $(\mathrm{CC})>$ South China Sea $(\mathrm{SCS})$. Meanwhile, the mean value of carcinogenic PAHs, non-carcinogenic PAHs, PAHs derived from the burning of organic matter, low molecular weight PAHs, medium molecular weight PAHs, and high molecular weight PAHs in 16 priority PAHs was $53.5 \%, 46.5 \%, 80.0 \%, 16.9 \%, 45.2 \%, 37.9 \%$, respectively. Moreover, from NW to $\mathrm{NC}$, the content and pollution of PAHs increased with the increase of population and gross domestic product (GDP). From CC to SW and NC, the content and pollution of PAHs increased with the increase of population and the decrease of GDP. From SW 
to NW and $\mathrm{CC}$ to $\mathrm{SC}$, the content and pollution of PAHs increased with the decrease in population and GDP. In part, PAHs pollution, characteristics and sources of atmospheric PM in Chinese cities broke the Hu line of population and GDP. Therefore, these require the promotion of comprehensive measures that will reduce pollution and sources of PAHs in heavily polluted areas.

Keywords: Hu line; Polycyclic aromatic hydrocarbons; Pollution; Atmospheric particulate matter; China

Capsule: To some extent, PAHs pollution, characteristics and sources of atmospheric PM broke the Hu line of GDP and population in China.

\section{Introduction}

PAHs in the atmosphere can be adsorbed into particulate matter (PM, Ma et al., 2020; Zheng et al., 2019; Zhu et al., 2019). With the growing urbanization process in China, PAHs pollution in PM is becoming a serious environmental problem (Zhao et al., 2020; Zhao et al., 2019). PM comprises suspended particles in the air, varying in composition and size, resulting from various anthropogenic activities, and consists of soil, building shedding, airborne particulates, fumes, and soot discharged from vehicles (Mao et al., 2020; Zheng et al., 2019). PAHs absorbed in PM can also be more easily transported (Ghanavati et al., 2019; Han et al., 2015) and remobilized into the atmosphere through volatilization, contributing to air pollution for long periods (Bai et al., 2019; Chen et al., 2019; Thang et al., 2019). PM is one of the most typical pollutants occurring in urban areas and it is used as an indicator of atmospheric quality. PM can also enter the human body via inhalation, ingestion, or dermal contact due to its long-range transportation remaining in the air periods (Kim et al., 2015; Liu 
et al., 2015a; Patra et al., 2016), which could increase risks on human health (Bortey-Sam et al., 2015; Yu et al., 2012). Since 2000, the increase in the levels of PAHs worldwide has increased, especially in those areas with greater urbanization and industrialization (Cao et al., 2018; Zhang et al., 2019). Some studies have also highlighted the problem of increasing contamination by PAHs in China due to its great population and industrial development. Therefore, there is a need to analyze to what extent it is increasing and how it relates to population and GDP on both sides of the Hu line (Cao et al., 2018; Liu et al., 2017; Ringuet et al., 2012; Zhang et al., 2019).

The content of PAHs in PM is source governed. PAHs come mainly from industrial and natural sources. In 2004, 520 thousand tons of PAHs were emitted into the atmosphere in global with consumer product usage (6.9\%), wildfire (17.0\%), biofuel (56.7\%) as the major sources (Zhang and Tao, 2009; Umweltbundesamt, 2016). China emitted 114 thousand tons more than any other country in the world in 2004 (Zhang and Tao, 2009). PAHs originate from human sources (industrial pyrolysis, city coal and oil heating, and the direct release of oil and its associated products, ship and automobile exhausts) and natural sources (forest fires, ancient sediment erosion, etc.) (Aryal et al., 2006; Brown et al., 2015; Li et al., 2020b; Pies et al., 2008; Schwarzbauer et al., 2000; Wang et al., 2009; Xu et al., 2006; Yuan et al., 2012; Zhang et al., 2008). However, due to a lack of long-term monitoring data, comparatively less attention has been paid to change trends of PAHs pollution, distribution, sources on both sides of the $\mathrm{Hu}$ line.

In summary, the above studies have shown that pollution caused by PAHs adsorbed in the atmospheric PM was very serious. However, there are remaining knowledge gaps and pending questions regarding the emission of PAHs, its pollution 
level and characteristics on both sides of the $\mathrm{Hu}$ line. As of today, the relationship between content and distribution of PAHs, population and GDP can reflect the extent to which production systems are cleaner. On both sides of the Hu line, its evaluation remains pending.

The $\mathrm{Hu}$ line (Hu Huanyong line or Heihe-Tengchong line) is a geographical line stretching from Heihe (a city in NE) to Tengchong (a city in SW), which divides China into two roughly equal parts, with a semi-arid region in the west and semi-humid region in the east (Chen, et al., 2019; Hu, 1935). Western China, 6\% of the nation's population lives on $57 \%$ of the land, is characterized by harsh areas (such as desert and alpine regions), and ecosystem degradation that is affecting human well-being and economic development. On the other side of the $\mathrm{Hu}$ line, the east has access to many natural resources, which have contributed towards a large-scale socio-economic and cultural development (Wang \& Deng, 2016; Zhang et al., 2018). Ninety-four percent of the nation's population lives on $43 \%$ of the land (Lu et al., 2016). This great imbalance that threatens industrial development, cleaner production, environmental sustainability, urbanization degree, and the most vulnerable populations is called the $\mathrm{Hu}$ line pattern (Zhang et al., 2015). There is a growing body of literature on the influence of the $\mathrm{Hu}$ line on and development of China (Hu et al., 2016; Zhang et al., 2015).

However, in the 20 years since China's accession to the World Trade Organization (WTO), were there any correlation relationships between the concentration, distribution and source of PAHs emitted by China's rapid economic and social development and the Hu line? Could pollution levels, characteristics, sources of PAHs in atmospheric particulate matter break the $\mathrm{Hu}$ line based on research in 2000-2019? 


\section{Data and methods}

\subsection{Data}

For nearly twenty years (2000-2019), PAHs in PM have become one of the pollutants of major concern in urban areas of China. Despite several studies on PAHs levels have been published, there are indeed disparities in variables such as energy consumption, development status, and the concentration of PAHs in PM in different urban areas. To better understand the pollution level and exposure of atmospheric PAHs throughout China, a large amount of information has been collected and processed. More than 6970 samples at more than 219 sites covering 93 urban areas in 34 provincial-level administrative regions and 7 background regions throughout China. The concentration levels of the 16 priority PAHs identified by the U.S. EPA, were collected from six major databases for the period 2000-2019: Science Direct (www.sciencedirect.com/), Springer Link (link.springer.com/), Wiley Online Library (onlinelibrary.wiley.com/) and three of the most common databases used in China, China National Knowledge Infrastructure (www.cnki.net/), Wanfang Data (www.wanfangdata.com.cn/index.html), and Cqvip (www.cqvip.com/). Data were collected from at least one city in each provincial-level administrative region. More details on these references can be found in the supplementary material (Table S1).

The following criteria were applied in the search of scientific literature. First of all, most relevant literature concerning PAHs pollution in PM from urban and background areas was included. The currently selected literature focused on research on the control of priority PAHs identified by the U.S. EPA (Keshavarzi et al., 2018). Furthermore, we aimed to evaluate the pollution across the whole country, selecting study sites thoroughly dispersed across the above prefecture-level city. The most recent data was always considered when multiple references were available for the 
same city. On the other hand, it has been taken into account the fact that after the implementation of reform and opening-up policy in China, there was a growing industrialization and urbanization process. In parallel, the PAHs pollution in the urban environment has become increasingly serious. Because of this, literature published in the last twenty years (2000-2019) was selected to study the impact of the rapid social-economic development experienced in China, on the pollution caused by PAHs, considering the increase of population and GDP, number of vehicles in use, the growing demand for energy and the increase in industrial production. The concentrations corresponding to the 16 priority PAHs according to U.S. EPA, time, number, and size of PM for all urban and background areas for each region are shown in Table S1 of the supplementary material.

The collected data corresponds to PAHs adsorbed on atmospheric fine particulate matter $\left(\mathrm{PM}_{2.5}\right)$, inhalable particulate matter $\left(\mathrm{PM}_{10}\right)$, and total suspended atmospheric particulate matter (TSP). Laboratory analysis, in general, has involved the extraction of PM samples with dichloromethane, acetone, n-hexane, or a mixture of these solvents. The total concentration of PAHs has generally been determined by gas chromatography (GC), gas chromatography-mass spectrometry (GC-MS), high-performance liquid chromatography-mass spectrometry (HPLC-MS) or high-performance liquid chromatography (HPLC) (Chai et al., 2017; Mo et al., 2019; Ohura et al., 2019; Soltani et al., 2019; Zhang, 2012; Zhu et al., 2019). These are validated and widely applied methodologies for the qualitative and quantitative analysis of PAHs.

\subsection{Geographical division of China}

Based on geographical conditions, climatical conditions and distance from 7 national atmospheric background monitoring stations (Mountain of Shengnongjia, 
Pangquangou, Waliguan, Nanling, Tengchong, Wuzhi, Changbai in Hubei, Shanxi, Qinghai, Guangdong, Yunnan, Hainan, Jilin province, respectively), China can be divided into 7 regions: NE, NC, NW, SC, SW, CC, SCS.

In this study, we collected data corresponding to the concentration of the $\sum$ 16PAHs from 93 urban areas, including 23 urban areas in 7 provinces or municipalities in CC (Hefei, Huainan and Tongling in Anhui; Wuhan, Yichang and Huangshi in Hubei; Changsha and Xiangtan in Hunan; Nanjing, Changzhou, Xuzhou, Wuxi, Zhenjiang and Nantong in Jiangsu; Nanchang and Jiujiang in Jiangxi; Shanghai; Hangzhou, Huzhou, Ningbo, Wenzhou, Taizhou and Jinhua city in Zhejiang); 19 urban areas in 7 provinces, autonomous region or municipalities in NC (Beijing; Shijiazhuang, Zhangjiakou, Baoding, Tangshan, Handan and Hengshui in Hebei; Zhengzhou and Xinxiang in Henan; Hohhot, Baotou, Dongsheng, Hangjin and Jungar Banner in Inner Mongolia; Jinan and Qingdao in Shandong; Taiyuan and Jinzhong in Shanxi; Tianjin); 12 urban areas in 5 provinces or autonomous region in NW (Xi'an and Yulin in Shaanxi; Lanzhou and Jinchang in Gansu; Yinchuan in Ningxia; Xining in Qinghai; Urumqi, Hotan, Miquan, Changji, Karamay and Shihezi in Xinjiang); 17 urban areas in 6 provinces in SC (Xiamen and Longyan in Fujian; Nanning, Baise and Liuzhou in Guangxi; Guangzhou, Shenzhen, Qingyuan, Shaoguan, Shantou and Dongguan in Guangdong; Macau; Hongkong; Taipei, Taichung, Miaoli and Hsinchu in Taiwan); 8 urban areas in 5 provinces, autonomous region or municipalities in SW (Chongqing; Mianyang and Chengdu in Sichuan; Guiyang in Guizhou; Lhssa and Linzhi in Xizang; Kunming and Yuxi in Yunnan); 13 urban areas in 3 provinces in NE (Harbin and Jiamusi in Heilongjiang; Changchun, Jilin, Siping, Tonghua and Baicheng in Jilin; Shenyang, Dalian, Jinzhou, Fushun, Anshan and Panjin in Liaoning); Haikou city in Hainan province in SCS (Table S1). 


\section{Results and discussion}

\subsection{Pollution level of PAHs in PM on both sides of the Hu line}

Fig. 1 summarized the concentrations of PAHs in airborne PM based on literature in 2000-2019. There were significant differences within the urban areas of the seven regions which took part in the surveys for the determination of the $\sum$ 16PAHs. In CC, NC, NW, SC, SW and NE, the concentrations that were detected were: Xuzhou $\left(164.6 \mathrm{ng} / \mathrm{m}^{3}\right)$, Jinzhong $\left(910.1 \mathrm{ng} / \mathrm{m}^{3}\right)$, Urumqi $\left(802.5 \mathrm{ng} / \mathrm{m}^{3}\right)$, Longyan (350.0 ng/m $\left.\mathrm{m}^{3}\right)$, Chongqing $\left(108.0 \mathrm{ng} / \mathrm{m}^{3}\right)$, Jilin $\left(1201.4 \mathrm{ng} / \mathrm{m}^{3}\right)$ with the highest levels of $\sum 16$ PAHs, respectively. Jinhua $\left(8.6 \mathrm{ng} / \mathrm{m}^{3}\right)$, Hangjin $\left(3.7 \mathrm{ng} / \mathrm{m}^{3}\right)$, Lanzhou (5.3 ng/m $\left.\mathrm{m}^{3}\right)$, Hsinchu $\left(1.8 \mathrm{ng} / \mathrm{m}^{3}\right)$, Linzhi $\left(0.5 \mathrm{ng} / \mathrm{m}^{3}\right)$, Harbin $\left(23.5 \mathrm{ng} / \mathrm{m}^{3}\right)$ with the lowest levels of $\sum 16 \mathrm{PAHs}$, respectively for the same regions. Unlike the above six regions, the concentration of PAHs in PM in Haikou was $4.7 \mathrm{ng} / \mathrm{m}^{3}$. The level of PAHs in PM for SCS did not experience significant increases compared to the other six regions. This, in turn, indicates good preservation of the environmental conditions or endowment in SCS, where existing measures control emissions of PAHs, given the fact that $\sum 16 \mathrm{PAHs}$ occurred in a relatively low level.

In Jilin and Linzhi city, the highest and lowest concentrations of PAHs ranged from 141.5 to $3100.1 \mathrm{ng} / \mathrm{m}^{3}$ and from below the detection limits (BDL) to $2.3 \mathrm{ng} / \mathrm{m}^{3}$, respectively. Across the whole of China, the level of $\sum 16 \mathrm{PAHs}$ in NE (mean 404.0 $\left.\mathrm{ng} / \mathrm{m}^{3}\right)$ was the highest and followed by $\mathrm{NC}\left(177.0 \mathrm{ng} / \mathrm{m}^{3}\right), \mathrm{NW}\left(169.1 \mathrm{ng} / \mathrm{m}^{3}\right), \mathrm{SC}$ $\left(57.2 \mathrm{ng} / \mathrm{m}^{3}\right), \mathrm{SW}\left(38.0 \mathrm{ng} / \mathrm{m}^{3}\right), \mathrm{CC}\left(29.0 \mathrm{ng} / \mathrm{m}^{3}\right)$ and SCS $\left(3.1 \mathrm{ng} / \mathrm{m}^{3}\right)$. Within NE, high levels of PAHs pollution were found in Jilin, Fushun, Shenyang. Lower levels of pollution were detected in CC, such as in Jinhua, Huzhou, Huangshi (Fig. 1 and Table S1). It can be seen that, in urban areas of China, contamination of PAHs absorbed in PM has been shown to have a higher incidence, indicating the need for mitigation 
measures to protect health.

\subsection{The relationship between PAHs pollution, population and GDP}

The pollution level of PAHs in PM in the whole of China was drawn by ArcGIS 10.2 (Fig. 2). As can be seen in Fig. 2, at similar latitude on both sides of the Hu line, from NW to NC, the concentrations and pollution levels of PAHs increase (Fig. 2a) with the increase of population (Fig. 2b) and GDP (Fig. 2c). From CC to SW, the concentrations and pollution level of PAHs increase with the increase of population and the decrease of GDP (Chen et al., 2019; Zhang et al., 2015; Zhang et al., 2020). While at similar longitudes on both sides of the $\mathrm{Hu}$ line, from NW to SW, the concentration and pollution of PAHs decrease with the increase of population and GDP. From NC to CC, the concentration and pollution of PAHs decrease with the decrease of population and the increase of GDP. From CC to SC, the concentration and pollution of PAHs increase with the decrease of population and GDP (Chen et al., 2019; Wang et al., 2016; Zhang et al., 2015; Zhang et al., 2020).

In Fig. $2 \mathrm{~b}$ and Table $\mathrm{S} 1$, the descending order of population in China, in millions of people, is as follows: $\mathrm{SW}(8.5)>\mathrm{NC}(7.0)>\mathrm{CC}(6.7)>\mathrm{SC}(4.7)>\mathrm{NE}(4.3)>\mathrm{NW}$ (2.8) $>$ SCS (2.3). In Fig. 2c and Table S1, the descending order of GDP in China, in billion yuan, is as follows: $\mathrm{CC}(850.2)>\mathrm{SC}(724.9)>\mathrm{SW}(708.8)>\mathrm{NC}(633.1)>\mathrm{NE}$ $(259.7)>\mathrm{NW}(211.6)>\operatorname{SCS}(167.2)$.

In Fig. 2b, Fig. 2c and Table S1, the average population in CC (6.7 million people) and NC (7.0 million people) is almost the same. Although the average GDP in $\mathrm{CC}$ ( 850.2 billion yuan) is 1.3 times higher than that in $\mathrm{NC}$ (633.1 billion yuan), PAHs pollution in $\mathrm{NC}\left(177.0 \mathrm{ng} / \mathrm{m}^{3}\right)$ is 6.1 times higher than that in CC $\left(29.0 \mathrm{ng} / \mathrm{m}^{3}\right)$. Similarly, the average population in SC (4.7 million people) and NE (4.3 million people) is nearly the same. Although the average GDP in SC (724.9 billion yuan) is 
2.8 times higher than that in NE (259.7 billion yuan), PAHs pollution in NE (404.0 $\left.\mathrm{ng} / \mathrm{m}^{3}\right)$ is 7.1 times higher than that in $\mathrm{SC}\left(57.2 \mathrm{ng} / \mathrm{m}^{3}\right)$.

Except for SCS, in the cold and dry NE, NC and NW, residential heating boiler, heavy industry and energy mining are the main emission sources (Yan et al., 2019; Zhang et al., 2016). These factors may be the key agents causing the significant lower GDP and higher PAHs pollution in NE, NC and NW. While in the warm and humid SW, CC and SC, light industry, textiles, electronics and electrical appliances, machinery manufacturing and other related industries are the main emission sources (Yan et al., 2019; Zhang et al., 2016). These factors may be the key agents causing the significantly higher GDP and lower PAHs pollution in SW, CC and SC. Therefore, the adjustment or upgrading of industrial structure and the implementation of a cleaner production strategy of industrial enterprises in NE, NC and NW is the main way to reduce PAHs pollution.

\subsection{Composition of PAHs in PM on both sides of the Hu line}

A similar proportion has been observed regarding the composition of the 16 PAHs in PM (Fig. 3 and 4). As shown in Table S1, the low molecular weight PAHs (LMW-PAHs, including species with 2 rings: Nap; 3 rings: Acy, Ace, Flu, Ant, Phe), medium molecular weight PAHs (MMW-PAHs, including species with 4 rings: Fla, Pyr, BaA, Chr) and high molecular weight PAHs (HMW-PAHs, including species with 5 rings: $\mathrm{BbF}, \mathrm{BkF}, \mathrm{BaP}, \mathrm{DA} ; 6$ rings: $\mathrm{BP}, \mathrm{IP})$ were detected in urban areas in the range of $0.1 \sim 221.3,0.1 \sim 850.0,0.3 \sim 564.1 \mathrm{ng} / \mathrm{m}^{3}$, with mean concentrations of 20.7, $62.0,51.2 \mathrm{ng} / \mathrm{m}^{3}$, respectively. Although the concentration levels varied significantly between urban areas, the composition of PAHs remained similar, being the main species MMW- and HMW-PAHs, since they accounted for $40 \%$ and $45 \%$ of the ¿16PAHs, respectively. The contribution of PAHs congeners in PM was also 
described by Li et al. (2016) and Wang et al. (2015) were similar.

In Fig. 4 and Table S2, according to the U.S. EPA, seven of $\Sigma 16$ PAHs are potentially carcinogenic (CAN-PAHs, Kong et al., 2010), including BaA, BbF, BkF, BaP, Chr, DA, and IP. The mean concentration of CAN-PAHs was $70.3 \mathrm{ng} / \mathrm{m}^{3}$, which varied from $0.3 \mathrm{ng} / \mathrm{m}^{3}$ in Linzhi to $937.1 \mathrm{ng} / \mathrm{m}^{3}$ in Jilin, accounting for $9.4 \%$ and $81.3 \%$ of the $\Sigma 16$ PAHs, respectively. Furthermore, the proportion of CAN-PAHs was similar, with a higher proportion (58.6\%) in $\mathrm{NC}$ and a lower proportion (47.7\%) in NW. The 9 remaining PAHs are potentially non-carcinogenic (NCAN-PAHs, Kong et al., 2010), including Nap, Acy, Ace, Flu, Ant, Phe, Fla, Pyr, and BP. The concentration of the NCAN-PAHs varied from $0.2 \mathrm{ng} / \mathrm{m}^{3}$ in Linzhi to $699.9 \mathrm{ng} / \mathrm{m}^{3}$ in Fushun, with an average concentration of $63.5 \mathrm{ng} / \mathrm{m}^{3}$, accounted for $18.7 \%$ and $90.6 \%$ of the $\Sigma 16$ PAHs, respectively. The proportion of the NCAN-PAHs also followed a similar pattern, with a higher proportion in NW toward a lower proportion in NC. Combustion-derived PAHs (COM-PAHs, Kong et al., 2010), which include Fla, Pyr, Chr, BbF, BkF, BaA, BaP, IP, and BP, are used to identify the combustion sources of PAHs. The content of COM-PAHs in urban areas varied from $0.3 \mathrm{ng} / \mathrm{m}^{3}$ in Linzhi to $1161.8 \mathrm{ng} / \mathrm{m}^{3}$ in Jilin, with a mean value of $109.5 \mathrm{ng} / \mathrm{m}^{3}$, accounting for 31.2 and $96.7 \%$ of the $\Sigma 16$ PAHs, respectively (Fig. 4 and Table S2).

It was observed that although the components of PAHs may differ depending on urban areas, the compositions of PAHs also vary across regions. This is the case for the $\mathrm{NC}\left(177.0 \mathrm{ng} / \mathrm{m}^{3}\right)$ and NW $\left(169.1 \mathrm{ng} / \mathrm{m}^{3}\right)$, the $\mathrm{SW}\left(38.0 \mathrm{ng} / \mathrm{m}^{3}\right)$ and $\mathrm{CC}(29.9$ $\mathrm{ng} / \mathrm{m}^{3}$ ), with comparable concentrations of $\sum 16 \mathrm{PAHs}$ but with different components. The content of HMW- and MMW-PAHs in NW and SW were relatively higher than NC and CC, respectively (Fig. 4 and Table S2). This may be in part due to the different sources of pollution among urban areas and/or the emissions and pollution 
characteristics.

\subsection{Pollution characteristics of PAHs in PM on both sides of the Hu line}

The maximum, minimum, background concentrations of PAHs in each region are shown in Fig. 5 and Table S3. In the mountains of Shennongjia, Pangquangou, Waliguan, Nanling, Tengchong, Wuzhi, and Changbai, the range background values were 0.1 to $3.4,1.1$ to $25.4,0.3$ to $7.8,0.1$ to $1.9,0.1$ to $17.0,1.8$ to $4.6,0.3$ to 8.1 $\mathrm{ng} / \mathrm{m}^{3}$, with average values of $1.9,12.0,2.1,0.6,2.4,3.1,2.7 \mathrm{ng} / \mathrm{m}^{3}$, respectively. Except for SCS, the maximum concentrations of PAHs, in six regions, were found in Xuzhou (164.6 ng/m³), Baotou (230.2 ng/m³), Urumqi (802.5 ng/m³), Longyan (350.0 ng/m $\left.\mathrm{m}^{3}\right)$, Chongqing $\left(108.0 \mathrm{ng} / \mathrm{m}^{3}\right)$, and Jilin $\left(1201.4 \mathrm{ng} / \mathrm{m}^{3}\right)$. The minimum concentrations of PAHs, in six regions, were found in Jinhua $\left(8.6 \mathrm{ng} / \mathrm{m}^{3}\right)$, Hangjin (3.7 ng/m $\left.\mathrm{m}^{3}\right)$, Lanzhou (5.3 ng/m $\left.\mathrm{m}^{3}\right)$, Hsinchu $\left(1.8 \mathrm{ng} / \mathrm{m}^{3}\right)$, Linzhi $\left(0.6 \mathrm{ng} / \mathrm{m}^{3}\right)$, and Harbin $\left(23.5 \mathrm{ng} / \mathrm{m}^{3}\right)$ (Fig. 5 and Table S3).

The maximum concentrations of PAHs were 86.6, 19.2, 382.1, 583.3, 45.0, and 445.0 times the background values detected in Shengnongjia $\left(1.9 \mathrm{ng} / \mathrm{m}^{3}\right)$, Pangquangou (12.0 ng/m $\left.\mathrm{m}^{3}\right)$, Waliguan $\left(2.1 \mathrm{ng} / \mathrm{m}^{3}\right)$, Nanling $(0.6 \mathrm{ng} / \mathrm{m} 3)$, Tengchong $\left(2.4 \mathrm{ng} / \mathrm{m}^{3}\right)$, and Changbai mountain $\left(2.7 \mathrm{ng} / \mathrm{m}^{3}\right)$ in the $\mathrm{CC}, \mathrm{NC}, \mathrm{NW}, \mathrm{SC}, \mathrm{SW}$, and NE, respectively. The minimum concentrations of PAHs were 4.5, 0.3, 2.5, 3.0, 0.2, 8.7 times background values detected in Shengnongjia, Pangquangou, Waliguan, Nanling, Tengchong, and in Changbai mountain, respectively. Besides, in Haikou city, the maximum $\left(5.3 \mathrm{ng} / \mathrm{m}^{3}\right)$, mean $\left(4.7 \mathrm{ng} / \mathrm{m}^{3}\right)$, minimum concentration $(4.1$ $\left.\mathrm{ng} / \mathrm{m}^{3}\right)$ of PAHs was $1.7,1.5,1.3$ times the background value $\left(3.1 \mathrm{ng} / \mathrm{m}^{3}\right)$ detected in Wuzhi mountain, respectively (Fig. 6 and Table S3).

The level of BaP, a highly carcinogenic compound, was also detected in urban areas in levels that varied from BDL in Linzhi to $61.6 \mathrm{ng} / \mathrm{m}^{3}$ in Jilin with a mean 
concentration of $6.7 \mathrm{ng} / \mathrm{m}^{3}$. The BaP concentrations in 73 of 93 urban areas, which accounted for $78.5 \%$, exceeded the limits established in $1.0 \mathrm{ng} / \mathrm{m}^{3}$ as annual mean content of $\mathrm{PM}_{10}$-bound BaP in China (Table S3 and S4; MEP and GAQSIQ, 2012) and the air quality standard set by the World Health Organization. On the other hand, in $\mathrm{CC}, \mathrm{NC}, \mathrm{NW}, \mathrm{SC}, \mathrm{SW}$, and $\mathrm{NE}$, it was found that the average $\mathrm{BaP}$ concentration exceeds the first-level concentration limit of $\mathrm{BaP}$ in the only $\mathrm{PM}_{10}$ in the ambient air quality standard (1.0 ng/m³, Table S3 and S4; MEP and GAQSIQ, 2012). Meanwhile, in $\mathrm{NC}, \mathrm{NW}, \mathrm{SC}$, and $\mathrm{NE}$, it was found that the average $\mathrm{BaP}$ concentration exceeds the second-level concentration limit of $\mathrm{BaP}$ in the only $\mathrm{PM}$ in the ambient air quality standard (2.5 ng/m³ , Table S3 and S4; MEP and GAQSIQ, 2012). Therefore, in NE (such as Jilin, Tonghua, Anshan), the level of pollution caused by BaP was also higher than that detected in CC (such as in Hangzhou, Huzhou and Jinhua; Table S3). These areas can be considered highly polluted and, therefore, require decision-making for better pollution management and control.

\subsection{Sources characteristics of PAHs in PM on both sides of the Hu line}

The highest and lowest average concentration of PAHs were 1201.4 and 0.6 $\mathrm{ng} / \mathrm{m}^{3}$, detected in Jilin and Linzhi, respectively. Jilin city is located in Jilin province in the NE, a highly industrialized city with a cold climate that requires the use of heating systems for several months (Li et al., 2005). Fushun city in Liaoning province, in NE, was also affected by the pollution of PAHs with the second-high concentration recorded. High levels of contamination in Fushun city may be due to activities related to oil processing, iron and steel smelting, and heating systems (Zhang, 2011). Linzhi city is located in Xizang in SW with little industrial activity (Chen et al., 2014).

Fig. 7 presents the ratio of different ring numbers of PAHs. Fig.7 and Table S2 show the proportion of LMW-, MMW-, and HMW-PAHs, concentrated in the range 
of $0.3-68.5 \%, 11.1-78.6 \%$, and $4.5-82.8 \%$, with an average value of $16.9 \%, 37.9 \%$, 45.2\%, respectively. Since the value of LMW-PAHs/HMW-PAHs was less than 1, presumably PAHs mainly derived from combustion sources (Yan et al., 2019). HMW-PAHs are primarily associated with coal sources, MMW-PAHs with biomass sources and LMW-PAHs with engine emissions (Duan et al., 2009; Xu et al., 2006; Yan et al., 2019; Zhang et al., 2016). The increase in the COM-PAHs may be related to human activities. Unlike for HMW-PAHs, given the lower weight and higher volatility of the LMW and MMW-PAHs, these can be transported over long distances by air over a long time (Hou et al., 2006; Hung et al., 2005; Wang et al., 2008). The ratio of (LMW- + MMW-PAHs)/HMW-PAHs was used to identify the sources of PAHs in PM (Hou et al., 2006; Li et al., 2016), in such a way that when the ratio has a low value indicates local emission, whereas a high ratio, a long-distance transportation (Hou et al., 2006). The mean ratio (2.0) was much lower than those in remote from the emission sources, implying that local emission was the main source for PAHs in PM. The ratio decreased from 21.2 to 0.2 with a median ratio (1.2), also indicating relatively local emission sources. Whereas the ratio in Dongguan (10.5), Nanning (21.1), Longyan (11.9), and Lhasa (10.1) were much higher. These results indicated clearly that in these cities most of the PAHs were likely from long-range transportation (Table S2, Hou et al., 2006; Li et al., 2016). This fact is in line with an increased proportion of HMW-PAHs. Besides, individual compounds implied different distribution patterns, that is, $\mathrm{BbF}, \mathrm{BP}$ and $\mathrm{IP}$ were dominant.

The compositions of PAHs were different across China, showing that the sources of LMW-, MMW-, and HMW-PAHs were different (Zhang et al., 2012; Zhang et al., 2018; Zhang et al., 2019). The composition profiles are affected depending on industrial production activities and the different emission patterns generated in urban 
areas. For example, in cities of NE, the emission sources of PAHs were predominantly from coal producers (Fu et al., 2016), while in NW and NC, from coal and firewood (Lu et al., 2015; Song et al., 2018; Ma et al., 2020).

Therefore, PAHs content in PM should be reducible by physical (such as situ cappings, sorption method of activated carbon, biochar, carbon nanotube, and their derivatives), chemical (such as incineration, thermal conduction, solvent extraction or soil washing, chemical oxidation), thermal and biological technologies (such as bioaugmentation, biostimulation, phytoremediation, composting or bio-piles, and bioreactors) during industrial production, winter heating, vehicles with energies, etc. (Kuppusamy et al., 2017; Li et al., 2020a; Li et al., 2020b).

As can be concluded from all information contained in this study, there are urban areas in China with high contamination of PAHs in PM. This study also reveals that the Hu line, delimits two very different areas, both socioeconomically, populationally and geographically, climatically, directly influencing the degree of contamination caused by PAHs. China's urban areas, densely populated and with further industrial development, are experiencing higher levels of pollution. With this analysis of information, the scientific value and applicability of this study were found. On the one hand, relevant control measures to reduce PAHs pollution should be formulated at the level of government and relevant administrative departments. Cutting consumption of coal and biomass by using green and clean energy (such as solar energy, wind energy, tidal energy, hydroelectric power and so on) as a substitute and applying fossil-fuel cleaning and green techniques are recommended for PAHs pollution control. More use of public transportation should be encouraged to lower emissions of PAHs into the atmosphere. Urban greening, planting trees, strengthening the control of PAHs pollution, and protecting the environment could be desirable solutions to pollution 
removal. On the other hand, at the level of individual protection, especially when residents are outdoors in the haze, sandstorms, fog and other heavy pollution weather, some protective measures should be taken to minimize the health risks caused by PAHs. Reducing outdoor exposure time and wearing a protective mask, gloves, glasses, etc. are recommended as effective means to avoid PAHs exposure.

\section{Conclusion}

This overview, for the first time, assesses the relationships between levels, composition, pollution, sources of PAHs in PM and population and GDP, at the above prefecture-level cities on both sides of the Hu line in China from 2000 to 2019. The pollution levels varied greatly among urban areas. Especially, the concentrations of PAHs in PM generally indicate that PAHs pollution is more severe in NE, NC, NW than in SCS, CC, SW. The proportions of HMW-PAHs and MMW-PAHs in CC, NE were relatively high compared with NE, SW, respectively. The total concentration corresponding to the $\sum 16 \mathrm{PAHs}$ was similar in NW and NC, SW and $\mathrm{CC}$, respectively. The highest levels of contamination were detected in NE. At the same time, the lower levels of pollution were distributed in SCS. In NE, NC, and NW, where the sources of PAHs were predominantly from coal and biomass. Moreover, the concentrations and pollution level of PAHs gradually increase according to the existing gradient of population density at the same latitude, from NW to NC and CC to SW. This finding is consistent with the level of population growth at both sides of the $\mathrm{Hu}$ line. While at the same longitude (from NW to SW, SC to $\mathrm{CC}$ ), the concentration and pollution of PAHs decreased significantly with the decrease of PAHs sources, and it is opposite to the level of GDP and population growth on both sides of the Hu line. Therefore, In a sense PAHs pollution, characteristics and sources of atmospheric PM broke the $\mathrm{Hu}$ line of GDP and population in China. To achieve sustainable development and the 
dream of "Beautiful China", China needs green, high quality, coordinated development, such as the implementation of measures for national rural revitalization, new urbanization or urban-rural integration development on both sides of the Hu line.

\section{Acknowledgments}

This work was supported by the Natural Science Foundation of Gansu Province (20JR10RA133), Innovation Fund of Colleges and Universities of Gansu Province (2021B-097), Longdong University Ph.D Candidate Scientific Research Fund (XYBY202004, XYBY1606) and NSFC through grant 41877516. The authors appreciate the valuable dedication of the reviewers and editors (Prof. Jiri Jaromir Klemeš, PhD Robert James Letcher and Prof. Dr. Jacob De Boer).

The viewpoints reflected in this paper are those of the authors and do not constitute endorsement or support of funding agencies.

\section{Appendix Supplementary data}

Supplementary data of this paper can be found online at https://doi.org/.

\section{References:}

Aryal, R.K., Furumai, H., Nakajima, F., Boller, M., 2006. Characteristics of particles associated PAHs in a first flush of a highway runoff. Water Sci. Technol. 53 (2), 245-251.

Bai, K., Ma, M., Chang, N.B., Gao W. 2019. Spatiotemporal trend analysis for fine atmospheric particulate matter concentrations in China using high-resolution satellite-derived and ground-measured $\mathrm{PM}_{2.5}$ data. J. Environ. Manage. 233, 530-542.

Bortey-Sam, N., Ikenaka, Y., Akoto, O., Nakayama, S.M., Yohannes, Y.B., Baidoo, E., Mizukawa, H., Ishizuka, M. 2015. Levels, potential sources and human 
ecology risk of polycyclic aromatic hydrocarbons (PAHs) in atmospheric particulate matter $\left(\mathrm{PM}_{10}\right)$ in Kumasi, Ghana. Environ. Sci. Pollut. Res. Int., 22, 9658-9667.

Brown, S.G., Eberly, S., Paatero, P., Norris, G.A., 2015. Methods for estimating uncertainty in PMF solutions: examples with ambient air and water quality data and guidance on reporting PMF results. Sci. Total Environ. 518-519, 626-635.

Cao, R., Zhang, H.J., Geng, N.B., Fu, Q., Teng, M., Zou, L.L., Gao, Y., Chen, J.P. 2018. Diurnal variations of atmospheric polycyclic aromatic hydrocarbons (PAHs) during three sequent winter haze episodes in Beijing, China. Sci. Total Environ., 625, 1486-1493.

Chai, C., Cheng, Q., Wu, J., Zeng, L., Chen, Q., Zhu, X., Ma, D., Ge, W. 2017. Contamination, source identification, and risk assessment of polycyclic aromatic hydrocarbons in the soils of vegetable greenhouses in Shandong, China. Ecotoxicol. Environ. Saf., 142, 181-188.

Chen, D.S., Zhao, Y.T., Yao, Y., Hong, Y., Guan, Q.F., Tu, W. 2019. Exploring the spatial differentiation of urbanization on two sides of the Hu Huanyong linebased on nighttime light data and cellular automata. Appl. Geogr. 112, 102081-102095.

Chen, Y., Cao, J., Zhao, J., Xu, H., Arimoto, R., Wang, G., Han, Y., Shen, Z., Li, G. 2014. N-alkanes and polycyclic aromatic hydrocarbons in total suspended particulates from the Southerneastern Tibetan Plateau: concentrations, seasonal variations, and sources. Sci. Total Environ., 470-471, 9-18.

Duan, F.K., He, K.B., Ma, Y.L., 2009. Concentration and sources of atmospheric polycyclic aromatic hydrocarbons (PAHs) in $\mathrm{PM}_{2.5}$ in Beijing. Acta Sci. 
Fu R., Guan Y.Q., Yang W.H., Meng Q., Cui G.Q., Lv, S., Dong, S.Y. 2016. Pollution characteristics and analysis of PAHs in ambient $\mathrm{PM}_{2.5}$ in Harbin. J. Environ. Health, 33, 429-432 (in Chinese with English abstract).

Ghanavati, N., Nazarpour, A., Watts, M.J. 2019. Status, source, ecological and ecology risk assessment of toxic metals and polycyclic aromatic hydrocarbons (PAHs) in street dust of Abadan, Iran. Catena, 177, 246-259.

Han, L., Cheng, S., Zhuang, G., Ning, H., Wang, H., Wei, W., Zhao, X. 2015. The changes and long-range transport of $\mathrm{PM}_{2.5}$ in Beijing in the past decade. Atmos. Environ., 110, 186-195.

Hou, X.M., Zhuang, G.S., Sun, Y.L., An, Z.S. 2006. Characteristics and sources of polycyclic aromatic hydrocarbons and fatty acids in $\mathrm{PM}_{2.5}$ aerosols in dust season in China. Atmos. Environ. 40, 3251-3262.

Hu, H.Y. 1935. Distribution of China's population. Acta Geographica Sinica, 2(2), $33-74$.

Hu, Z.C., Wang, Y.L., Liu, Y.S., Long, H.L., Pneg, J. 2016. Spatio-Temporal Patterns of Urban-Rural Development and Transformation in East of the "Hu Huanyong Line”, China. Int. J. Geo-Inf. 2016, 5, 24; doi:10.3390/ijgi5030024.

Hung, H., Blanchard, P., Halsall, C.J., Bidleman, T.F., Stern, G.A., Fellin,,P., Muir, D.C.G., Barrie, L.A., Jantunen, L.M., Helm, P.A., Ma, J., Konoplev, A. 2005. Temporal and spatial variabilities of atmospheric polychlorinated biphenyls (PCBs), organochlorine (OC) pesticides and polycycli caromatic hydrocarbons (PAHs) in the Canadian Arctic: results from a decade of monitoring. Sci. Total Environ. 342, 119-144.

Keshavarzi, B., Abbasi, S., Moore, F., Mehravar, S., Sorooshian, A., Soltani, N., 
Najmeddin, A. 2018. Contamination Level, Source Identification and Risk Assessment of Potentially Toxic Elements (PTEs) and Polycyclic Aromatic Hydrocarbons (PAHs) in Street Dust of an Important Commercial Center in Iran. Environ. Manage. 62, 803-818.

Kim, K.H., Kabir, E., Kabir, S. 2015. A review on the human ecology impact of airborne atmospheric particulate matter. Environ. Int., 74, 136-143.

Kong, S., Ding, X., Bai, Z., Han, B., Chen, L., Shi, J., Li, Z. 2010. A seasonal study of polycyclic aromatic hydrocarbons in $\mathrm{PM}_{2.5}$ and $\mathrm{PM}_{2.5-10}$ in five typical cities of Liaoning Province, China. J. Hazard. Mater. 183, 70-80.

Kuppusamy, S., Thavamani, P., Venkateswarlu, K., Lee, Y.B., Naidu, R., Megharaj, M., 2017. Remediation approaches for polycyclic aromatic hydrocarbons (PAHs) contaminated soils: technological constraints, emerging trends and future directions. Chemosphere 168, 944-968.

Li, C.R., Cui, J.F., Li, Y.H., Jing, L.J., 2005. Study on distribution characteristics of PAHs in inhalable particles in industry area in Jilin City. J. Jilin Inst. Chem. Technol. 22, 1249-1251.

Li, F., Chen, J.J., Hu, X., He, F., Bean, E., Tsang, D.C.W., Ok, Y.S., Gao, B., 2020a. Applications of carbonaceous adsorbents in the remediation of polycyclic aromatic hydrocarbon-contaminated sediments: A review. J. Clean. Prod. 255, 120263-120275.

Li, R.F., Hua, P., Zhang, J., Krebs, P., 2020b. Characterizing and predicting the impact of vehicular emissions on the transport and fate of polycyclic aromatic hydrocarbons in environmental multimedia. J. Clean. Prod. 271, 122591-122602.

Li, X.X., Kong, S.F., Yin, Y., Li, L., Yuan, L., Li, Q., Xiao, H. 2016. Polycyclic 
aromatic hydrocarbons (PAHs) in atmospheric $\mathrm{PM}_{2.5}$ around 2013 Asian Youth Games period in Nanjing. Atmos. Res. 174-175, 85-96.

502

Liu, D., Lin, T., Syed, J.H., Cheng, Z., Xu, Y., Li, K., Zhang, G., Li, J. 2017.

Concentration, source identification, and exposure risk assessment of $\mathrm{PM}_{2.5}$-bound parent PAHs and nitro-PAHs in atmosphere from typical Chinese urbans. Sci. Rep., 7, 10398-10409.

Liu, X., Zhai, Y., Zhu, Y., Liu, Y., Chen, H., Li, P., Peng, C., Xu, B., Li, C., Zeng, G. 2015. Mass concentration and ecology risk assessment of heavy metals in size-segregated airborne atmospheric particulate matter in Changsha. Sci. Total Environ., 517, 215-221.

Lu, D.D., Wang, Z., Feng, Z.M., Zeng, G., Fang, C.L., Dong, X.F., Liu, S.H., Jia, S.F., Fang, Y.P., Meng, G.W., Deng, X.Z., Ye, C., Cao, G.Z., Du, H.R., Zhang, H., Ma, H.T., Chen, M.X. 2016. Academic debates on Hu Huanyong population line. Geogr. Res., 35, 805-824. (In Chinese with English abstract) https://doi.org/10.11821/dlyj201605001

Lu, W., Yang, L., Chen, J., Wang, X., Li, H., Zhu, Y., Wen, L., Xu, C., Zhang, J., Zhu, T., Wang, W. 2015. Identification of concentrations and sources of $\mathrm{PM}_{2.5}$-bound PAHs in North China during haze episodes in 2013. Air Qual., Atmos. Ecology, 9, 823-833.

Ma, L.X., Li, B., Liu, Y.P., Sun, X.Z., Fu D.L., Sun, S.J., Thapa, S., Geng, J.L., Qi, H., Zhang, A.P., Tian, C.G. 2020. Characterization, sources and risk assessment of $\mathrm{PM}_{2.5}$-bound polycyclic aromatic hydrocarbons (PAHs) and nitrated PAHs (NPAHs) in Harbin, a cold city in North China. J. Cleaner Prod., https://doi.org/10.1016/j.jclepro.2020.121673.

Mao, Y., Hu, T.P., Shi, M.M., Liu, M., Cheng, C., Liu, W.J., Zhang, J.Q., Qi, S.H., 
Xing, X.L. 2020. $\mathrm{PM}_{2.5}$-bound PAHs during a winter haze episode in a typical mining city, central China: Characteristics, influencing parameters, and sources. Atmos. Pollut. Res., https://doi.org/10.1016/j.apr.2020.03.005.

MEP and GAQSIQ (Ministry of Environmental Protection, General Administration of Quality Supervision, Inspection and Quarantine, PRC). 2012. Ambient air quality standards (GB 3095-2012).

Mo, Z., Z. Wang, G. Mao, X. Pan, L. Wu, Xu, P., Chen, S., Wang, A., Zhang, Y., Luo, J., Ye, X., Wang, X., Chen, Z., Lou, X. 2019. Characterization and ecology risk assessment of $\mathrm{PM}_{2.5}$-bound polycyclic aromatic hydrocarbons in 5 urbans urbans of Zhejiang Province, China. Sci. Rep., 9, 7296-7306 (in Chinese with English abstract).

Ohura, T., Suhara, T., Kamiya, Y., Ikemori, F., Kageyama, S., Nakajima, D. 2019. Distributions and multiple sources of chlorinated polycyclic aromatic hydrocarbons in the air over Japan. Sci. Total Environ., 649, 364-371.

Patra, A.K., Gautam, S., Kumar, P. 2016. Emissions and human ecology impact of atmospheric particulate matter from surface mining operation-A review. Environ. Technol. Inno., 5, 233-249.

Pies, C., Hoffmann, B., Petrowsky, J., Yang, Y., Ternes, T.A., Hofmann, T., 2008. Characterization and source identification of polycyclic aromatic hydrocarbons (PAHs) in river bank soils. Chemosphere 72 (10), 1594-1601.

Ringuet, J., Albinet, A., Leoz-Garziandia, E., Budzinski, H., Villenave, E. 2012. Reactivity of polycyclic aromatic compounds (PAHs, NPAHs and OPAHs) adsorbed on natural aerosol particles exposed to atmospheric oxidants. Atmos. Environ., 15-22.

Schwarzbauer, J., Littke, R., Weigelt, V., 2000. Identification of specific organic 
contaminants for estimating the contribution of the Elbe river to the pollution of the German Bight. Org. Geochem. 31 (12), 1713-1731.

Soltani, N., Moore, F., Keshavarzi, B., Sorooshian, A., Javid, R. 2019. Potentially toxic elements (PTEs) and polycyclic aromatic hydrocarbons (PAHs) in fish and prawn in the Persian Gulf, Iran. Ecotox. Environ. Saf., 173, 251-265.

Song, Q.Q., Wang, Y.H., Li, S., Jia, Q., Luo, B., Su, L.M., Liu, Q., Yuan, X.R., Niu, J. P. 2018. Source apportionment of PAHs in fine atmospheric particulate matter in urbans area in Lanzhou. J. Environ. Heal., 35, 162-165 (in Chinese with English abstract).

Thang, P.Q., Kim, S.J., Lee, S.J., Ye, J., Seo, Y.K., Baek, S.O., Choi, S.D. 2019. Seasonal characteristics of particulate polycyclic aromatic hydrocarbons (PAHs) in a petrochemical and oil refinery industrial area on the western coast of Southern Korea. Atmos. Environ., 198, 398-406.

Umweltbundesamt, 2016. Polycyclic Aromatic Hydrocarbons: Harmful to the Environment! Toxic! Inevitable? German Environment Agency.

Wang, C., Dao, X., Zhang, L.L., Lv, Y.B., Teng, E.J. 2015. Characteristics and toxicity assessment of airborne particulate polycyclic aromatic hydrocarbons of four background sites in China. China Environ. Sci., 35, 3543-3549. (in Chinese with English abstract).

Wang, D., Tian, F., Yang, M., Liu, C., Li, Y.-F., 2009. Application of positive matrix factorization to identify potential sources of PAHs in soil of Dalian, China. Environ. Pollut. 157 (5), 1559-1564.

Wang, K., Deng, Y. 2016. Can new urbanization break through the Hu Huanyong line:further discussion on the geographical connotations of the Hu Huanyong line. Geogr. Res., 35(5), 825-835 (in Chinese with English abstract). 
Wang, X.F., Cheng, H.X., Xu, X.B., Zhuang, G.M., Zhao, C.D. 2008. A wintertime study of polycyclic aromatic hydrocarbons in $\mathrm{PM}_{2.5}$ and $\mathrm{PM}_{2.5-10}$ in Beijing: Assessment of energy structure conversion. J. Hazard. Mater. 157, 47-56.

Xu, S.S, Liu, W.X., Tao, S. 2006. Emission of polycyclic aromatic hydrocarbons in China. Environ. Sci. Technol. 40, 702-708.

Yan, D.H., Wu, S.H., Zhou, S.L., Tong, G.J., Li, F.F., Wang, Y.M., Li, B.J. 2019. Characteristics, sources and ecology risk assessment of airborne particulate PAHs in Chinese urbans: A review. Environ, Pollut., 248, 804-814.

Yu, Y.J., Wang, Q., Nan, Z.R., Zhang, Y.P., Lin, H.P., Wang, S.L. 2012. Distribution characteristics and ecology risk assessment of heavy metal pollutants on air atmospheric particulate matters in Lanzhou city. Adv. Mater. Res., 518-523, 961-969.

Yuan, B., Shao, M., de Gouw, J., Parrish, D.D., Lu, S., Wang, M., Zeng, L., Zhang, Q., Song, Y., Zhang, J., 2012. Volatile organic compounds (VOCs) in urban air: how chemistry affects the interpretation of positive matrix factorization (PMF) analysis. J. Geophys. Res.: Atmosphere 117 (D24).

Zhang, H., Wang, R., Xue, H., Hu, R., Liu, G. 2018. Characteristic and source of atmospheric $\mathrm{PM}_{10^{-}}$and $\mathrm{PM}_{2.5}$-bound $\mathrm{PAHs}$ in a typical metallurgic city near Yangtze river in China. Bull. Environ. Contam. Toxicol., 100, 303-309.

Zhang, J., Yang, L., Ledoux, F., Courcot, D., Mellouki, A., Gao, Y., Jiang, P., Li, Y., Wang, W. 2019. $\mathrm{PM}_{2.5}$-bound polycyclic aromatic hydrocarbons (PAHs) and nitrated PAHs (NPAHs) in rural and suburbans regions in Shandong and Henan Provinces during the 2016 Chinese New Year's holiday. Environ. Pollut., 250, 782-791.

Zhang, M., Xie, J.F., Wang, Z.T., Zhao, L.J., Zhang, H., Li, M. 2016. Determination 
and source identification of priority polycyclic aromatic hydrocarbons in $\mathrm{PM}_{2.5}$ in Taiyuan, China. Atmos. Res., 178-179, 401-414.

Zhang, M., Sun, X.R., Wang, W.W. 2020. Study on the effect of environmental regulations and industrial structure on haze pollution in China from the dual perspective of independence and linkage. J. Cleaner Prod., https://doi.org/10.1016/j.jclepro.2020.120748.

Zhang, Y., Dou, H., Chang, B., Wei, Z., Qiu, W., Liu, S., Liu, W., Tao, S., 2008. Emission of polycyclic aromatic hydrocarbons from indoor straw burning and emission inventory updating in China. Ann. N. Y. Acad. Sci. 1140 (1), 218-227.

Zhang, Y. X., Tao, S. 2009. Global atmospheric emission inventory of polycyclic aromatic hydrocarbons (PAHs) for 2004. Atmos. Environ., 43, 812-819.

Zhang, Y. Y., Song, Y. J., Zhang, C. Y. 2015. The new urbanization and the possibility of breaking through the "Hu line". Journal of East China Normal University, $02,101-112$

Zhang, Z.Y. 2012. Study on the distribution characters of PAHs ire atmospheric particulate matter in typical urbans of Jilin Province. Doctoral Thesis of Jilin University, 27. (in Chinese with English abstract).

Zhao, T., Yang, L.X., Huang, Q., Zhang, W., Duan, S.F., Gao, H.L, Wang, W.X., 2020. $\mathrm{PM}_{2.5}$-bound polycyclic aromatic hydrocarbons (PAHs) and nitrated-PAHs (NPAHs) emitted by gasoline vehicles: Characterization and ecology risk assessment. Sci. Total Environ., 727, 138631-791.

Zhao, Z., Lv, S., Zhang, Y., Zhao, Q., Shen, L., Xu, S., Yu, J., Hou, J., Jin, C. 2019. Characteristics and source apportionment of $\mathrm{PM}_{2.5}$ in Jiaxing, China. Environ. Sci. Pollut. Res. Int, 26, 7497-7511. 
625 Zheng, L., Ou, J., Liu, M., Chen, Y., Tang, Q., Hu, Y. 2019. Seasonal and spatial

626

627

628

629

630

631

632 variations of $\mathrm{PM}_{10}$-bounded PAHs in a coal mining city, China: Distributions, sources, and health risk. Ecotoxicol. Environ. Saf., 169, 470-478.

Zhu, J., Hsu, C.Y., Chou, W.C., Chen, M.J., Chen, J.L., Yang, T.T., Wu Y.S., Chen, Y.C. 2019. $\mathrm{PM}_{2.5^{-}}$and $\mathrm{PM}_{10}$-bound polycyclic aromatic hydrocarbons (PAHs) in the residential area near coal-fired power and steelmaking plants of Taichung City, Taiwan: In vitro-based ecology risk and source identification. Sci. Total Environ., 670, 439-447. 
Figures

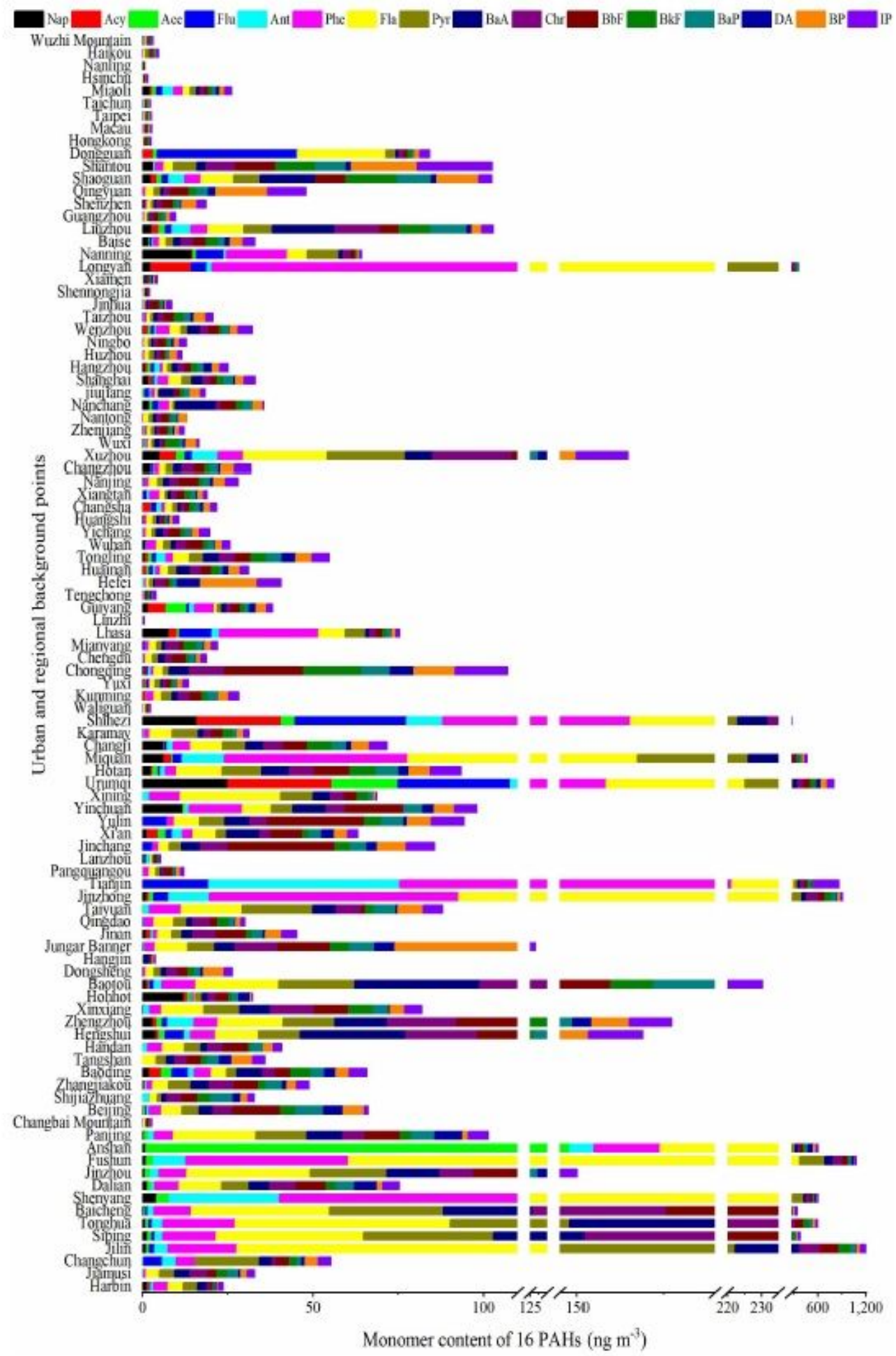

Figure 1

PAHs concentrations in Chinese cities and regional background sites. 


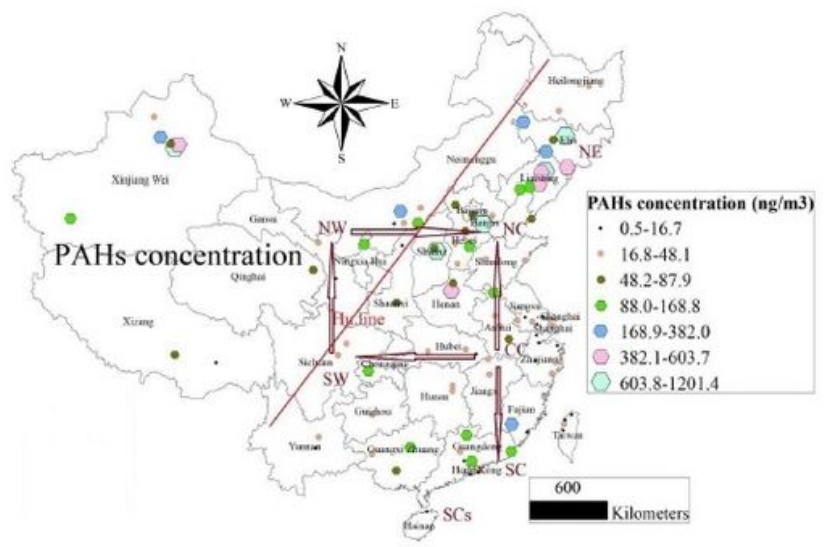

b
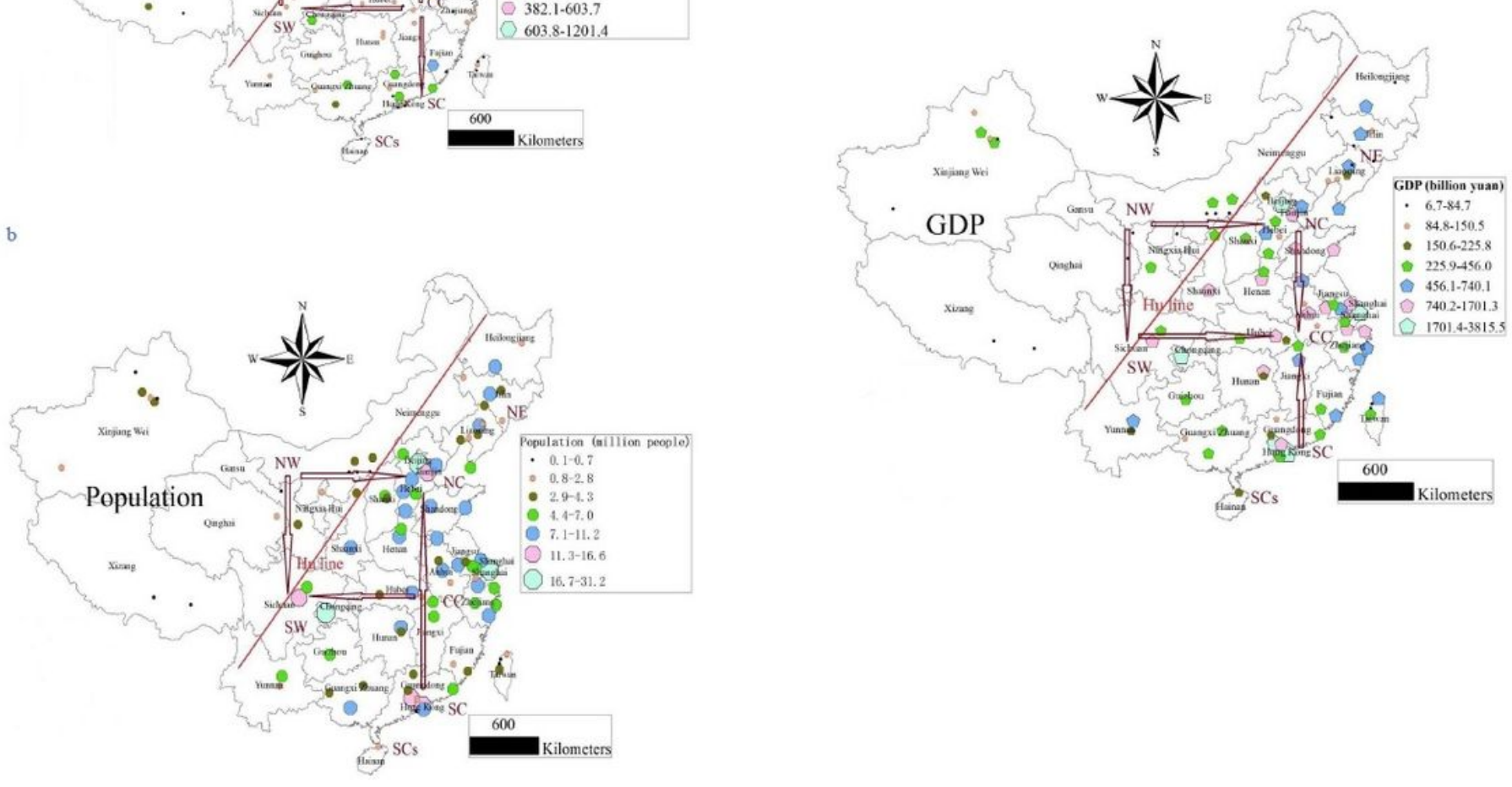

Figure 2

Pollution level of PAHs, population and GDP in Chinese cities. Note: The designations employed and the presentation of the material on this map do not imply the expression of any opinion whatsoever on the part of Research Square concerning the legal status of any country, territory, city or area or of its authorities, or concerning the delimitation of its frontiers or boundaries. This map has been provided by the authors. 


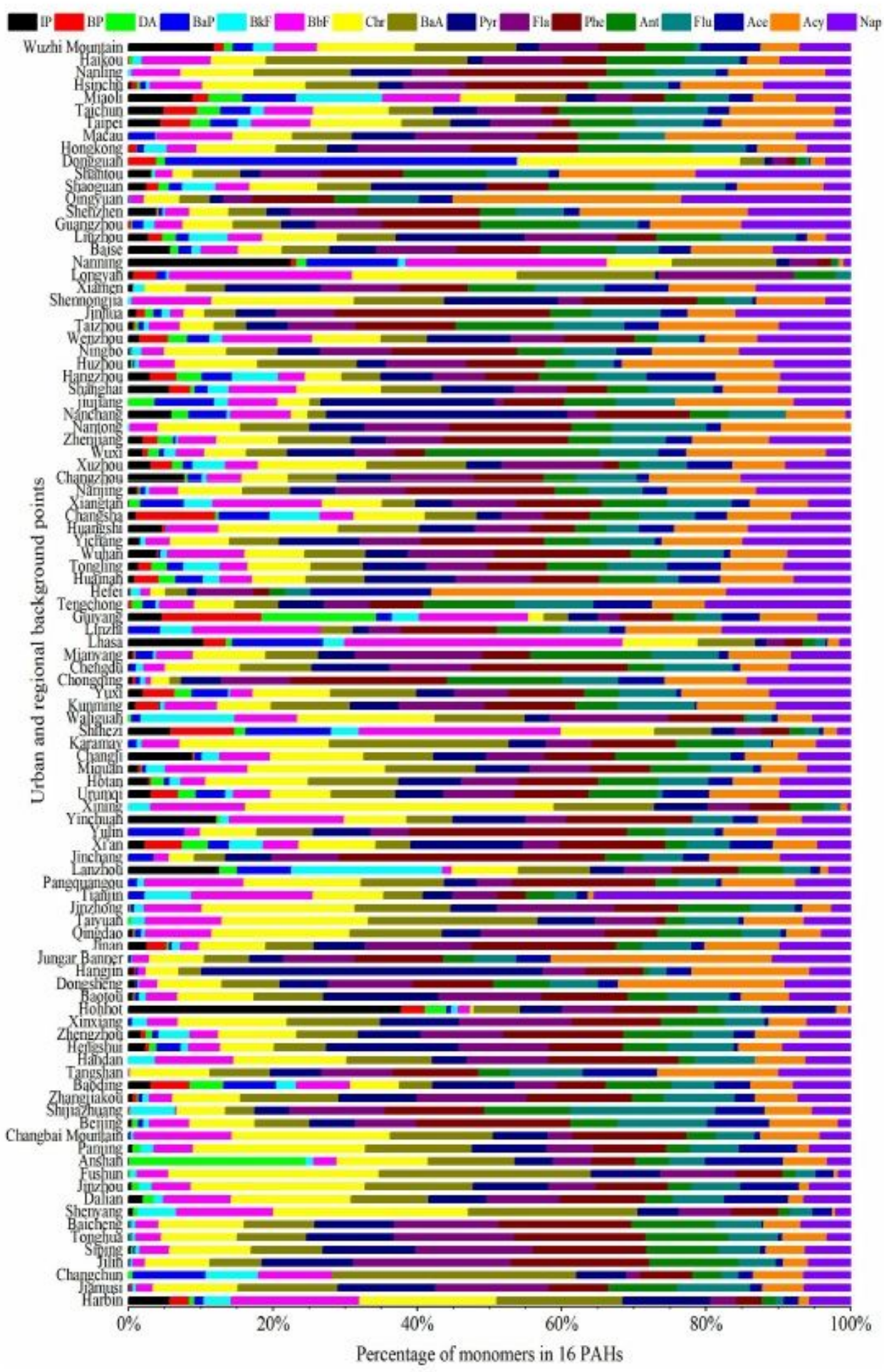

\section{Figure 3}

Percentage of monomer PAHs in Chinese cities. 


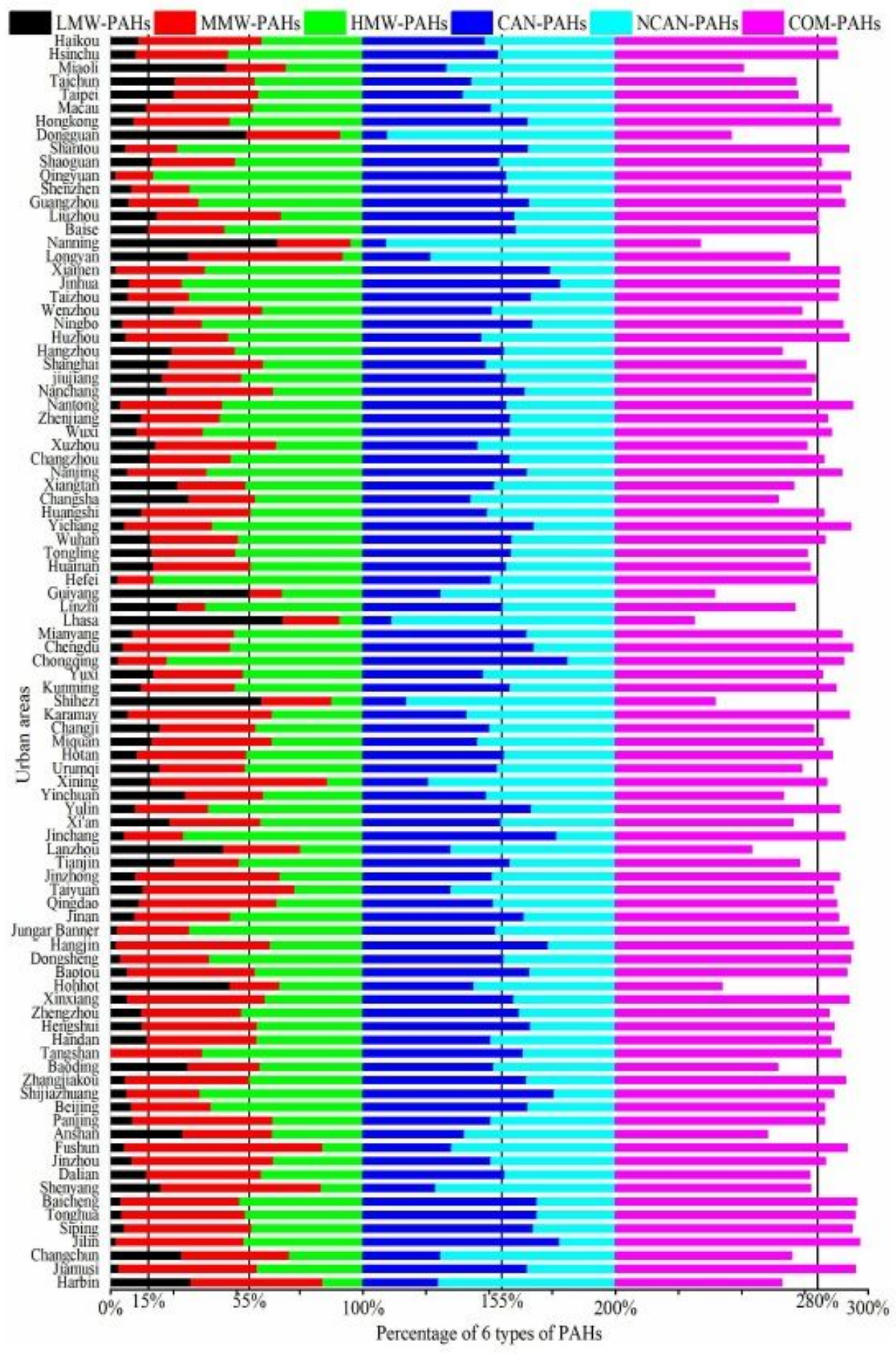

\section{Figure 4}

Proportion of 5 types of PAHs in Chinese cities. 


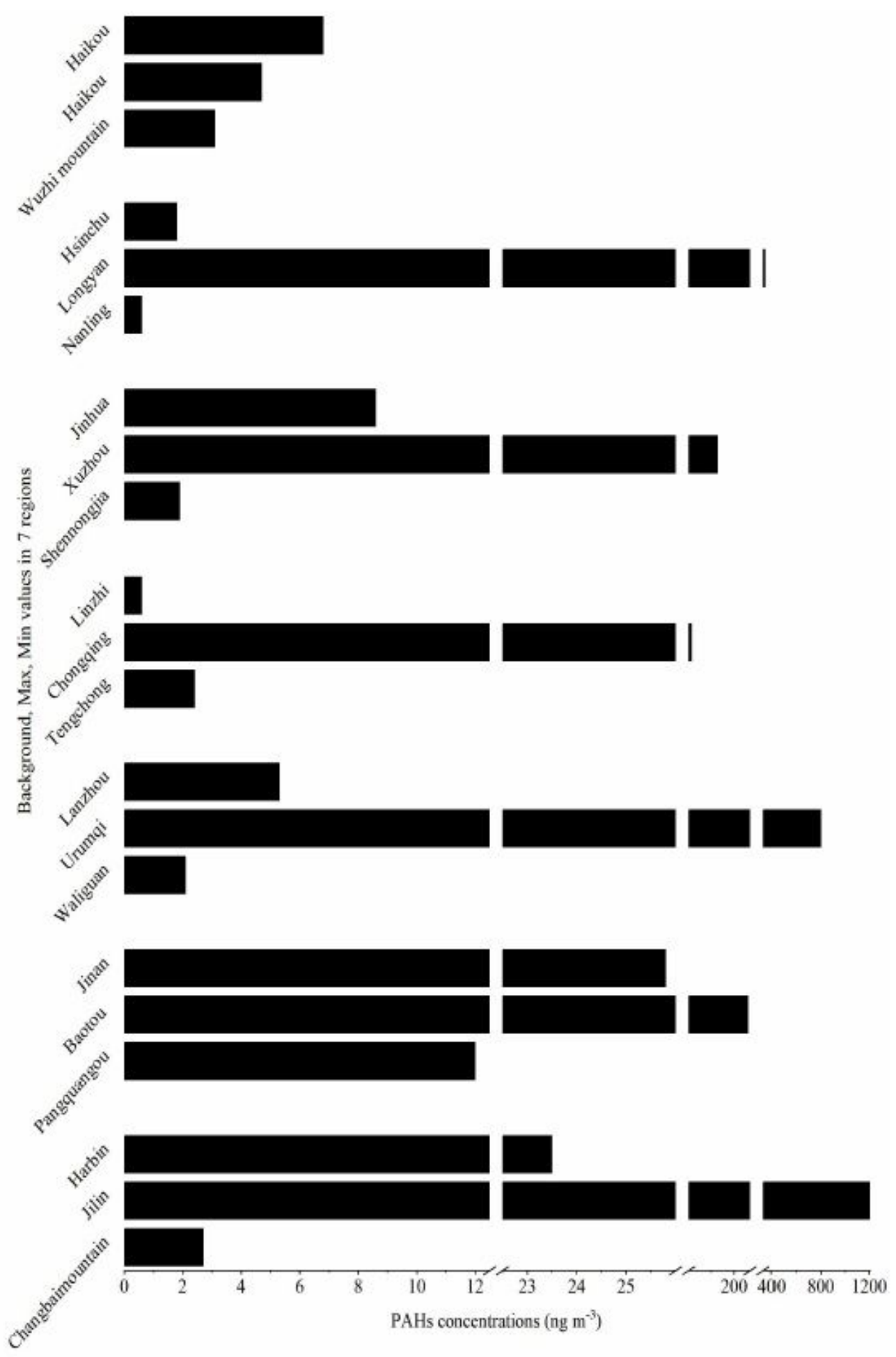

Figure 5

PAHs concentrations of background, max, min values in 7 regions. 


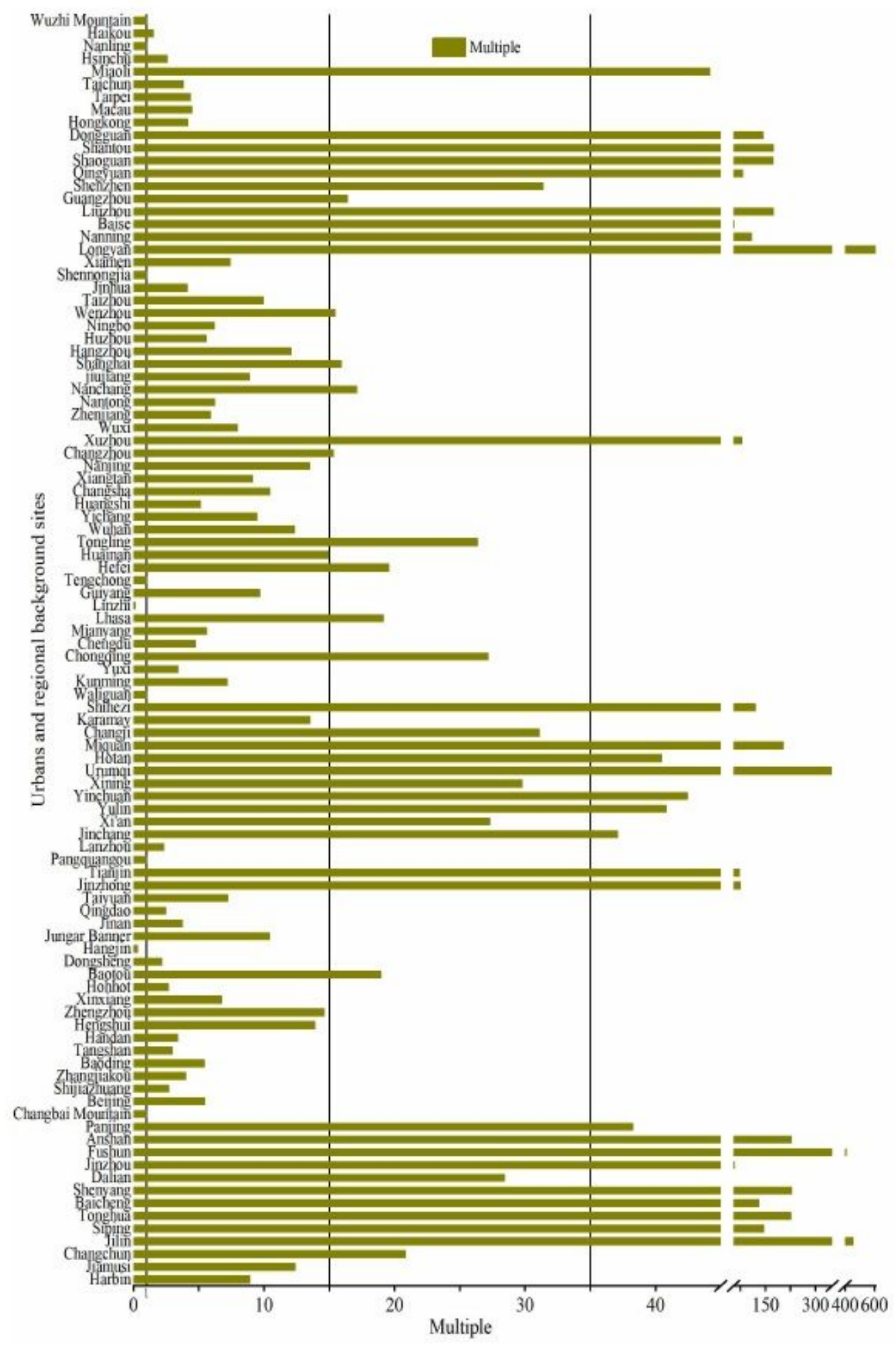

Figure 6

Multiple relationships of PAHs concentrations between cities and regional background sites. 


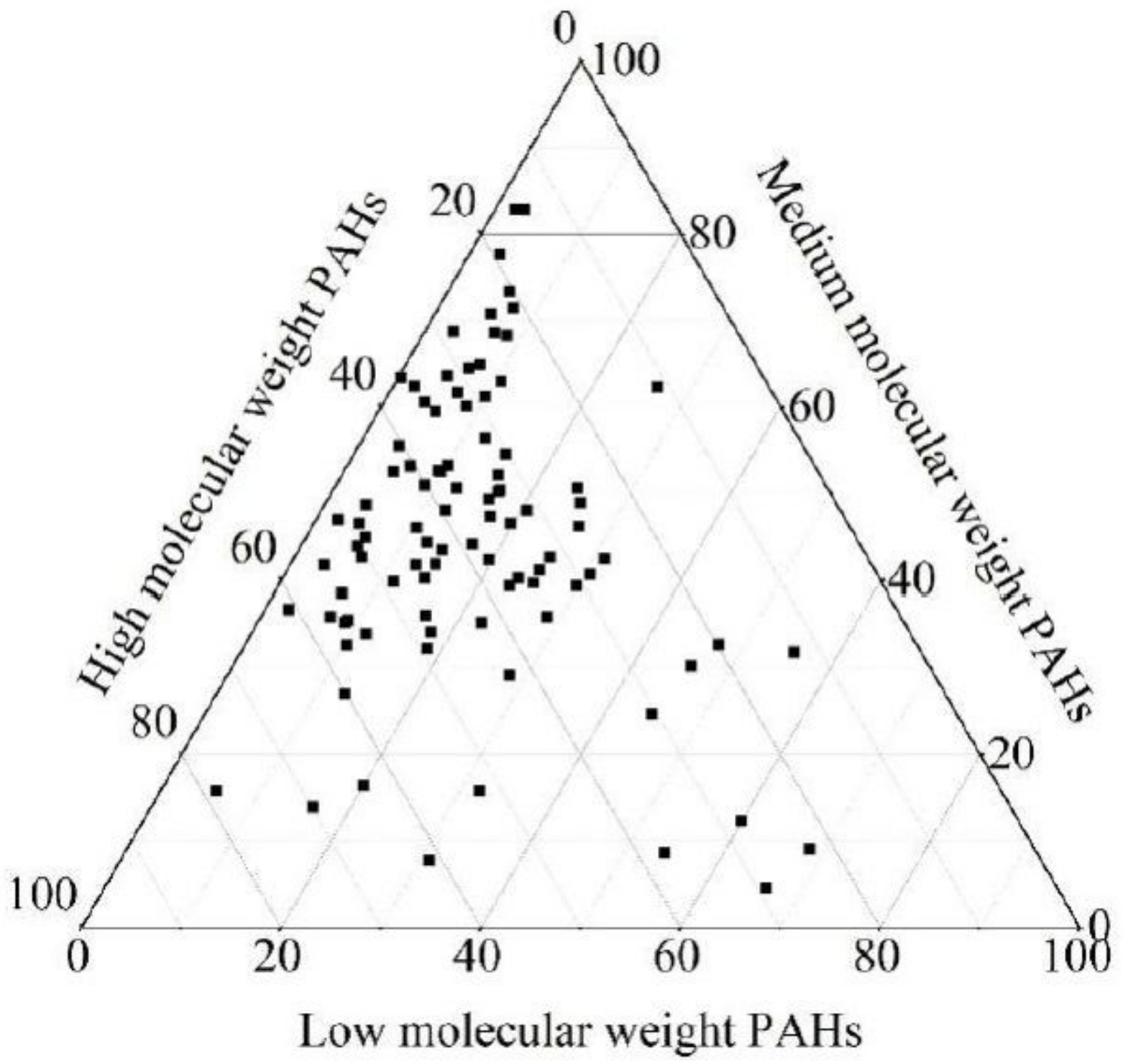

Figure 7

Triangle diagram of the ratio of PAHs with different ring numbers in PM.

\section{Supplementary Files}

This is a list of supplementary files associated with this preprint. Click to download.

- 2021.1.19Supplementarymaterial.pdf 